\title{
Medical diagnosis as a linguistic game
}

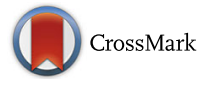

\author{
Peter Fritz ${ }^{1}$, Andreas Kleinhans², Florian Kuisle ${ }^{2}$, Patricius Albu², Christine Fritz-Kuisle ${ }^{3}$ and Mark Dominik Alscher ${ }^{2^{*}}$ (i)
}

\begin{abstract}
Background: We present a formalized medical knowledge system using a linguistic approach combined with a semantic net.

Method: Diseases are defined and coded by natural linguistic terms and linked via a complex network of attributes, categories, classes, lists and other semantic conditions.

Results: We have isolated more than 4600 disease entities (termed pathosoms using a made-up word) with more than 100.000 attributes sets (termed pathophemes using a made-up word) and a semantic net with more than 140.000 links. All major-medical thesauri like ICD, ICD-O and OPS are included.

Conclusions: Memem7 is a linguistic approach to medical knowledge approach. With the system, we performed a proof of concept and we conclude from our data that our or similar approaches provides reliable and feasible tools for physicians given a formalized history taking is available. Our approach can be considered as both a linguistic game and a third opinion to a set of patient's data.
\end{abstract}

Keywords: Formalized medical knowledge, Medical data base, Linguistic game, Disease entity

\section{Background}

Medicine involves doctors and patients discussing risk and reaching complex decisions together about treatment options, amongst other things. Yet it is known that diagnostic errors occur, with a frequency (depending on how terms are defined) ranging between $2.5 \%$ and $20 \%$ $[1,2]$. Most errors have only moderate negative consequences, but some do not. Modern computing technology is claimed to decrease the number of erroneous diagnosis [3-5]. Nowadays, numerous systems of collecting patient data (electronic history taking systems) exist. Only generalist publications are cited ([5-16], for review $[5,16])$. Our approach has as starting point the fact that the collection of patient data can be considered as a patient data vector. Assignment of the symptoms or signs of a patient to a certain diagnosis is possible by a bundle of different not exclusive methods: (1) by the knowledge of the physician, (2) by comparison of the patient data with clinical pathways and guidelines, (3) by boards of specialized physicians, (4) a second opinion by an experienced medical doctor, and (5) by computer-assisted comparison with a data base of medical knowledge. The

\footnotetext{
* Correspondence: Dominik.Alscher@rbk.de

${ }^{2}$ Department of General Internal Medicine and Nephrology,

Robert-Bosch-Hospital, Auerbachstrasse 110, D-70376 Stuttgart, Germany

Full list of author information is available at the end of the article
}

approach proposed in (5) implies, that we use formalized systems allowing sampling of medical knowledge (prototypic diseases) in a formalized manner. We describe thereafter a database of prototypes of diseases, which are oriented on the concept of vectors (patient vectors and disease vectors). For this approach three constituents are necessary: (1) patient vector, (2) a pool of disease vectors (described in this paper) (3) an algorithm allowing an interaction between both vectors. For the approach mentioned in (2) and (3) clinical decision support systems (CDSS and inference engine technology) are available [17-19]. Most approaches concerning computer-assisted data bases of medical knowledge are based on classical object-oriented structures and an entity-relationshipmodel. Substantial improvement of CDSS may be provided by IT-systems improving knowledge acquisition such as MetaMap [20] and cTake [21].

Our system shows that it is possible to use original atomistic language element and an intuitive, flexible semantic network to get medical context and structures which allow complex diagnostic understanding. The diagnosis process appears as a system driven dialogue which tries to match system semantics with patient semantics. This procedure can be understood as a "linguistic game", which provides a "third opinion" for the patient's symptoms. 


\section{Methods}

For the demonstration of our approach we used 4 examples of patients, fitting the symptoms of these patients to possible disease entities (pathosoms in our terminology).

\section{Examples}

Case 1: The patient suffers from cytopenia, anemia and bone marrow: hypercellular (3 tuple, one with an attribute).

Case 2: A female, aged 55 years suffering from a firm lump in the mamma (2-tuple with 1 and 2 attributes).

Case 3: A newborn suffering from "polydactyly", "renal cyst" and "encephalocele" (3-tuple).

Case 4: A female patient suffering from proteinuria, hematuria and fever (3-tuple).

\section{Thesauri}

A thesaurus was defined as a collection of atomistic terms with a coding system (numeric, alpha-numeric or string). Many thesauri could be obtained from Internet or official institutions as the DIMDI (Deutsches Institut für medizinische Dokumentation) [22]. Examples of such medical thesauri are: ICD (International Classification of Diseases, injuries and causes of death [23], ICD-O (International Classification of Diseases, Oncology) [24], ORPHANET (Portal für seltene Krankheiten und Orphan Drugs) [25], TA (Taxonomy of Anatomy) [26], OPS (Operationen-und Prozedurenschlüssel -Internationale Klassifikation der Prozeduren in der Medizin 2015) [27], OMIM (Online Mendelian Inheritance in Man) [28], CAS (common chemistry data base) [29], EC (comprehensive enzyme information system) [30], HGNC (Hugo Gene Nomenclature Committee 2015) [31], ATC (Anatomical Therapeutic Chemical Classification) [32] and LOINC (Logical Observation identifiers and names) [33]. All these thesauri terms and codes are harmonized and included in Memem7 using our own coding system with links to the original code.

\section{Software}

The system is focused on design flexibility using common website programming development environments like common SQL databases and Javascript.

\section{Atomistic approach}

Each descriptor of a symptom or sign (pathological sign, laboratory sign, EKG report (electrocardiogram) or genetic findings are transformed to an atomistic term. Atomistic terms are the basic form of our system. An atomistic term can be considered as a stem word with a singular code and some added attributes. One example of such an atomistic term is proteinuria with a numeric attribute $(\mathrm{g} / \mathrm{ml})$ or headache with the attribute: strong. Attributes may be cardinal, ordinal or numeric.

\section{Prototypic diseases (pathosom)}

A disease entity or a prototype of a disease is considered as the sum of all descriptors in a WHO classification or clinical pathway. All these descriptors must be atomic (see below for definition of a pathophem). Pictures are, so far, included by internet links. All these descriptors were class-divided as shown in Table 1. A pathosom is therefore defined as the sum of a vector: $c(j 1 \ldots . j n)$. Each element $j$ can be assigned to certain classes (see Table 1) or thesaurus (see Table 2).

\section{Pathophem}

A pathophem is an object sentence in a classification, clinical pathway or a publication after its atomistic representation. After this breakdown, we have an object (a single word meaning a stem word in the linguistic sense) which can be further characterized by up to three attributes or any object. Attributes are time, intensity, color, taste etc. Each object can be either true or false or not available. Objects should be coded by the thesaurus systems as given in Table 2. All content is coded along our coding system and then termed pathophem. In addition, occurrence probabilities between 0 and 1 can be considered. "Lead" means that this pathophem is always present in a pathosom and signifies a probability of 1 , " +++ " means a frequency between $50 \%$ to $99.9 \%$ or a probability of $0.5-0.99$, “++" means a frequency of $10 \%$ to $49.9 \%$ or a probability of $0,1-0.49$, “+” $1 \%$ to $9.9 \%$ or a probability of $0.01-0.09$, and “ $(+)$ " $<1 \%$ or a probability $<0.01$. "NOT" means that a pathophem excludes a pathosom.

\section{Diagnostic algorithm (linguistic game)}

The algorithm uses various syntactical and semantic analysis procedures to provide a set of diagnoses. Proposal of diagnoses occurs by matching a patient vector (medical report replaced in our test system by a 5-tuple vector of patient data) with the disease vectors (termed pathosoms). First the patient vector must be analyzed syntactically. This verification ensures that all terms are within the basic thesauri and have a "primary meaning" within the semantic network. Our semantic network is a classical semantic network for knowledge representation. It is a directed graph consisting of vertices, which represent terms, objects and concepts, and edges, which represent semantic relations between terms like "is-a", "is-part-of", "has-attribut-of", "is-class-of".

There will be a continuous dialog by offering alternative meanings if all terms are completely matched using synonyms, clarifying double meanings etc. The 
Table 1 Classes of Memem7

\begin{tabular}{|c|c|c|c|c|}
\hline No & Class & Subclass & Subclass2 & Elements \\
\hline 1100 & Description & Definition & & 7241 \\
\hline 1400 & Description & System/Lokalisation & & 9875 \\
\hline 1500 & Description & Struktur & ElementOf & 1733 \\
\hline 1540 & Description & Struktur & HasElement & 6251 \\
\hline 1550 & Description & Struktur & HasVariante & 1651 \\
\hline 1570 & Description & Struktur & Sekundare Form & 177 \\
\hline 5100 & Symptoms & Anamnese & & 7406 \\
\hline 5110 & Symptoms & Anamnese & Akut & 182 \\
\hline 5130 & Symptoms & Anamnese & Vorgeschichte & 479 \\
\hline 5140 & Symptoms & Anamnese & Familie & 47 \\
\hline 5150 & Symptoms & Anamnese & Demografisch & 10 \\
\hline 5160 & Symptoms & Anamnese & Sozial & 88 \\
\hline 5300 & Symptoms & Vital & & 7597 \\
\hline 5400 & Symptoms & Physikal & & 768 \\
\hline 5410 & Symptoms & Physikal & Spirometry & 22 \\
\hline 5500 & Symptoms & Labor & & 4423 \\
\hline 5510 & Symptoms & Labor & Clinical & 696 \\
\hline 5520 & Symptoms & Labor & Agent & 1370 \\
\hline 5530 & Symptoms & Labor & Toxicology & 35 \\
\hline 5600 & Symptoms & Imaging & & 401 \\
\hline 5610 & Symptoms & Imaging & Ultrasound & 119 \\
\hline 5620 & Symptoms & Imaging & Radiology & 570 \\
\hline 5630 & Symptoms & Imaging & MRT & 187 \\
\hline 5640 & Symptoms & Imaging & $\mathrm{CT}$ & 132 \\
\hline 5650 & Symptoms & Imaging & Endoskopie & 16 \\
\hline 5700 & Symptoms & Pathologie & & 1795 \\
\hline 5710 & Symptoms & Pathologie & Makroskopie & 1252 \\
\hline 5720 & Symptoms & Pathologie & Mikroskopie & 8576 \\
\hline 5725 & Symptoms & Pathologie & Elektronenmikroskopie & 291 \\
\hline 5730 & Symptoms & Pathologie & Spezialfarbung & 236 \\
\hline 5735 & Symptoms & Pathologie & Enzymhistochemie & 96 \\
\hline 5738 & Symptoms & Pathologie & Zytologie & 894 \\
\hline 5740 & Symptoms & Pathologie & Immunhistochemie & 3596 \\
\hline 5745 & Symptoms & Pathologie & FACS & 29 \\
\hline 5750 & Symptoms & Pathologie & In-Situ Hybridisierung & 39 \\
\hline 5760 & Symptoms & Pathologie & Molekularbiologie & 30 \\
\hline 5770 & Symptoms & Pathologie & Stoffe & 95 \\
\hline 5795 & Symptoms & Pathologie & Differenzialdiagnose & 1356 \\
\hline 5800 & Symptoms & Genetik & & 4400 \\
\hline 5900 & Symptoms & Psychologie & & 175 \\
\hline 6100 & Characteristics & Historie & & 83 \\
\hline 6300 & Characteristics & Epidemologie & & 2029 \\
\hline 6310 & Characteristics & Epidemologie & Sex & 557 \\
\hline 6320 & Characteristics & Epidemologie & Age & 989 \\
\hline
\end{tabular}


Table 1 Classes of Memem7 (Continued)

\begin{tabular}{|c|c|c|c|c|}
\hline 6330 & Characteristics & Epidemologie & Race & 66 \\
\hline 6340 & Characteristics & Epidemologie & Region & 132 \\
\hline 6350 & Characteristics & Epidemologie & Inzidenz & 198 \\
\hline 6360 & Characteristics & Epidemologie & Pravalenz & 528 \\
\hline 6400 & Characteristics & Atiologie & & 607 \\
\hline 6500 & Characteristics & Pathophysiologie & & 2783 \\
\hline 6600 & Characteristics & Verlauf & & 588 \\
\hline 6610 & Characteristics & Verlauf & Beginn & 236 \\
\hline 6620 & Characteristics & Verlauf & Verlauf & 266 \\
\hline 6630 & Characteristics & Verlauf & Stadium & 462 \\
\hline 6640 & Characteristics & Verlauf & Prognose & 1122 \\
\hline 6650 & Characteristics & Verlauf & Komplikation & 1506 \\
\hline 6660 & Characteristics & Verlauf & Risikofaktor & 965 \\
\hline 6700 & Characteristics & Komorbiditat & & 1316 \\
\hline 6800 & Characteristics & Differentialdiagnose & & 7785 \\
\hline 6900 & Characteristics & Untersuchung & & 3016 \\
\hline 8100 & Therapy & Therapieprinzipien & & 1422 \\
\hline 8200 & Therapy & Medikamente & & 2302 \\
\hline 8300 & Therapy & Chirurgie & & 493 \\
\hline 8400 & Therapy & Strahlentherapie & & 32 \\
\hline 8500 & Therapy & Ambulance & & 8 \\
\hline 8600 & Therapy & ReHa & & 44 \\
\hline 8700 & Therapy & Psychotherapie & & 7 \\
\hline 8800 & Therapy & Alternative & & 369 \\
\hline 9800 & Therapy & Vorsorge & & 326 \\
\hline
\end{tabular}

Table 2 Thesauri in medical use [21-29, 35, 36, 38]

\begin{tabular}{lll}
\hline Thesaurus (acronym) & Content of diseases & $\begin{array}{l}\text { Free available and } \\
\text { used in memem7 }\end{array}$ \\
\hline ICD-10-GM & Diseases & yes \\
ICD-O & Morphology of tumors & yes \\
ORPHANET & Rare Diseases & yes \\
OPS & Medical interventions & yes \\
LOINC & Laboratory Codings & yes \\
SNOMED & Medical terms and ontology & no \\
OMIM & Human genes/Genetic & yes \\
& Disorders & \\
TA & Taxanomica anatomica & yes \\
CAS & Molecules & yes \\
EC & Enzymes & yes \\
HGNC & Molecular biological terms & yes \\
ATC & Agents/Medicaments & yes \\
\hline
\end{tabular}

first result will be a set of matching pathosoms with a ranking. If the set is too large the system provides a second analysis to reduce the set by asking more details about other essential symptoms of the pathosoms. If the set is very small or empty the system tries to broaden the patient vector by using semantic network context methods like "is-class" and others. For example: If you are searching for a concrete finger symptom/pathophem and you cannot find anyone there might be a corresponding symptom/pathophem about the hand which may fit.

\section{Linguistic problems (German/English)}

More than $85 \%$ of the used terms are already translated in English.

\section{Statistical methods}

For calculations, we used $\mathrm{R}$ statistic package (version 3.1.1). For analysis of the ICD-10 (German version) we used the tm package of $R$ [34]. The question to be answered was of how many atomized terms the ICD-10 consisted of and to integrate those lacking in memem7. 


\section{Description of software}

- Project name: Memem7 Medical Semantic Network

- Project home page: not yet determined

- Archived version: not yet determined

- Operating system(s): Platform independent

- Programming language: Coldfusion, Javascript, HTML5

- Other requirements: Coldfusion Server

- License: Not yet determined

- Any restrictions to use by non-academics: Not yet determined

\section{Evaluation of Memem7}

Testing the quality of Memem7 was done with 190 artificial reports (simulated cases not representing a patient), originally developed for testing CLEOS [3-5]. Each artificial case consists of a short medical report and/ or symptoms with a mono-causal medical explanation.

\section{Results}

\section{Examples for using Memem7 for searching}

This means comparing the patient vector (a tuple with up to 5 elements) with the set of pathosoms, looking for those pathosoms which fits best to the patient vector using a linguistic approach.

\section{Case 1}

The search terms in English are cytopenia (41), anemia (657), bone marrow (91): hypercellular. This is a patient vector with 3 elements. The numbers in parenthesis signify how often a pathophem is mentioned in Memem7. For the intersection of the three pathophems only one pathosom was found, namely RAEB (M3501, see Additional file 1).

\section{Case 2}

The search terms are female (597): aged 55 years, nodule (365): firm (90), nodule: mamma (434). The pathosom invasive breast cancer was found and (excluding the attribute firm) 6 additional pathosoms are proposed: angiosarcoma of breast, secretory breast cancer, benign breast tumor, pseudoangiomatoid stroma hyperplasia, fibroadenoma and breast papilloma were recognized.

\section{Case 3}

The search terms are polydactyly (40), renal cyst (14), encephalocele (6) in a newborn infant. 3 pathosoms fitted to the search terms: Meckel syndrome type 1,3,6.

\section{Case 4}

The search terms are being proteinuria (61) and hematuria (72). As a result, 25 pathosoms are given by
Memem7 as possible disease vectors fitting both symptoms. Adding fever (622) to the atomistic terms gives 8 additional pathosoms: cryoglobulinemia with vasculitis, periarteriitis nodosa, microscopic polyangiitis, hanta virus infection, hemorrhagic fever with with renal syndrome, emphysematous pyelonephritis, infective glomerulonephritis and acute interstitial nephritis.

\section{Examples of pathosoms fitting the cases 1-4 Case 1: RAEB (refractory anemia with excess of blasts)}

As an example, we have chosen the disease entity of RAEB being a subset of myelodysplasia. This entity is described by two pages (pp100-101, 22] in the WHO classification of tumors of hematopoietic and lymphoid tissue [35]. The ICD-10-GM coding is D46.2. The ICD-O-coding 9983/3. The first sentence is: refractory anemia with excess blasts is a myelodysplastic syndrome (MDS) with 5-19\% myeloblasts in the bone marrow (BM) or $2-19 \%$ blasts in the peripheral blood. In our system, this sentence is transformed in a vector with atomistic terms: c (refractory anemia, myeloblasts: bone marrow > 5\%: AND: myeloblasts: bone marrow < 20\%) OR (blasts: peripheral blood $>2 \%$ ). The whole Boole term must be TRUE. This is an example of generating pathophemes in the pathosom RAEB. The coded version of this sentence is: M3094|; (O812| \& 10209|: 5..20\%) | (10221 T| \&10209 T|: 2..20\%). For details see also Additional file 1: Tables S1 to S3.

\section{Case 2: invasive breast cancer}

Invasive breast cancer is a set of clinical and morphological diseases with a hierachical structure. There are 68 pathosoms of breast cancer including terms like non-invasive breast cancer, inflammatory breast cancer (see Additional file 1: Tables S5 and S6) or tubular carcinoma of breast, which are structured in a tree ("is-element", "has-element", "has-variant"). One example of these 68 pathosoms (inflammatory breast cancer) is given in Table 3 and Additional file 1: Tables S5 and S6.

\section{Case 3: genetic disorder of skeletal disease}

For this example, we used the Meckel syndrome type IV (see Table 4) [36, 37]. The atomistic terms are coded. If different codes are available from different thesauri the selection of the assignment is random. As shown in Table 1, 6 different synonyms or codes (such as the OMIM code 612284) are provided in our system allowing to collect further information.

\section{Case 4: membrano-proliferative glomerulonephritis (MPGN) (see Table 5)}

Classification of MPGN is a set of three subsets termed MPGN Type I, MPGN type II and MPGN type III [38]. The ICD coding is N05.5, N04.5, N03.5, N02.5, and N01.5 (see Additional file 1: Tables S7 and S8). 
Table 3 Part of the pathosom breast cancer with concern to anamnesis and examination by the physican (Vital)

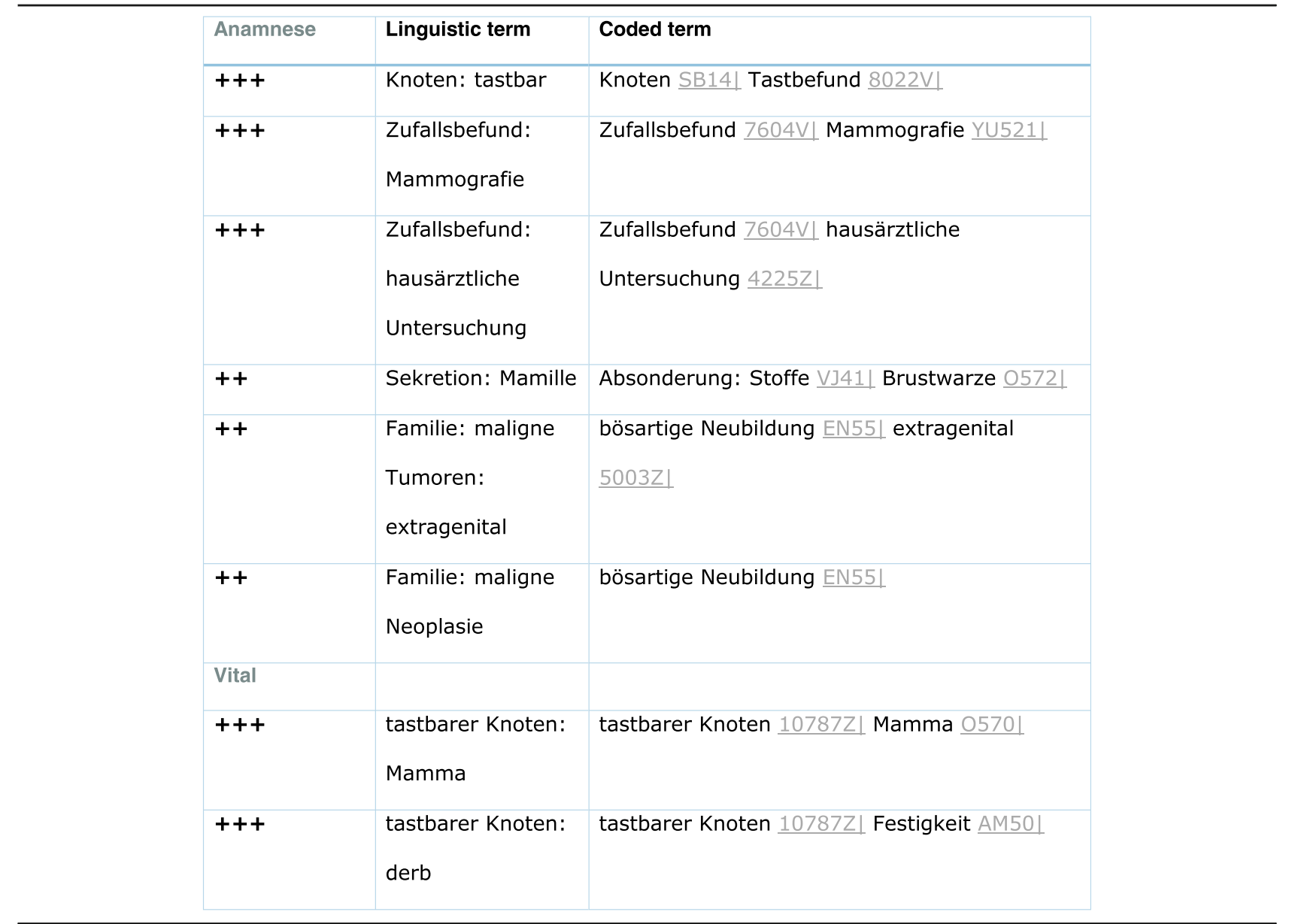

Note that "tastbarer Knoten is coded by $10787 Z$ and this code includes lump and palpable node

\section{Description of Memem7 \\ Thesauri}

The thesauri used in our system are listed in Table 2. For the example RAEB (refractory anemia with excess of blasts) we have one alpha-numeric code ICD-10 D46.2. In the other thesauri RAEB is not mentioned. In the ICD-O classification [23], however, this disease entity is mentioned by the term refractory cytopenia with multilineage dysplasia. For the second example with genetic caused skeletal disorder different ICD-10 codes are available (ICD-10 Q65.-Q79.9). With the tm text analysis system of R, we obtained a list of 53947 atomized terms. $16798(31.1 \%)$ of these ICD-10 terms were originally not part of memem 7 and were integrated in the system. Mallet finger (Hammerfinger in German) is part of ICD-10 (M20.0), but originally not of Memem7. Tm identifies the term Hammerfinger as element of ICD-10 and this term was added to Memem7 (including its counterpart in English). The number of diagnoses in the ICD-10 code (not signs, symptoms) was estimated to $\sim 9700$.

\section{Number of pathosoms and pathophemes}

By now approx. 4600 pathosoms (prototypic diseases) with 104.200 pathophemes (prototypic symptoms) are included in our system. For writing the atomized pathophems we provide terms taken from different thesauri (see Table 2). In total, there are approx. 230.000 terms coded out of 1.550.000 terms including German, English and Latin in different grammatical forms. Therefore, Memem7 covers $~ 4600 / 9700(47.2 \%)$ of the diagnoses of the ICD-10 classification system. We assume that each pathosom consists of at least $10 \ldots 100$ pathophemes depending of the complexity of the disease.

\section{Comparison of pathosom and diagnosis}

A pathosom is a data model which describes knowledge about a disease in a structured but flexible, nondeterministic way. It also may be considered as a vector of pathophems, each of them being TRUE (1), FALSE (0), or by an evidence between 0 and 1 . A diagnosis is either an alpha-numeric code such as a ICD-10 code [23, 24, 35] or a written description of a disease such as refractory 


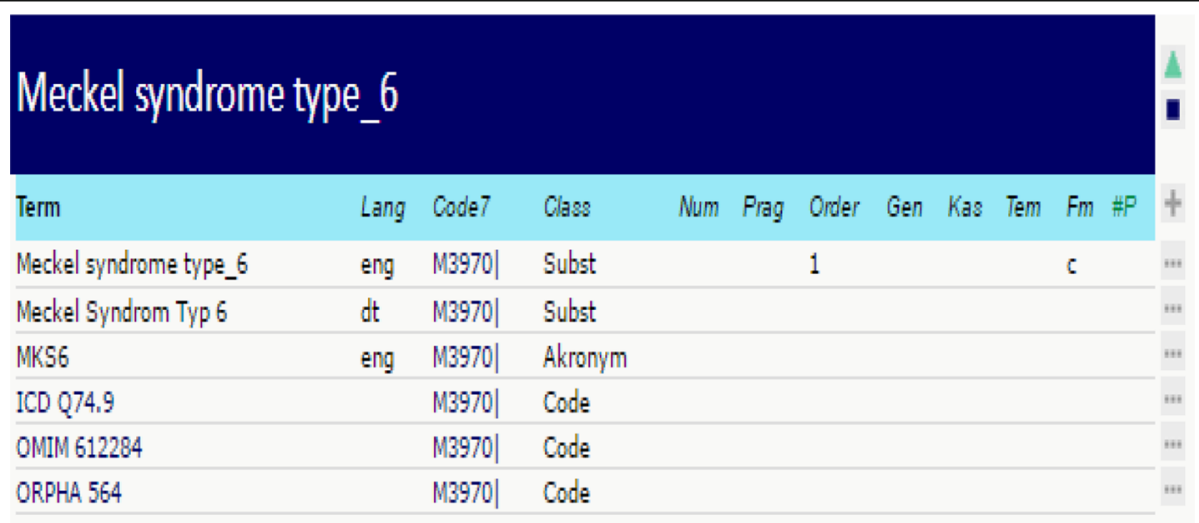

\begin{tabular}{|c|c|}
\hline Definition Texte / Web / Media & Type \\
\hline W Wikipedia: Meckel syndrome type_ 6 & web \\
\hline 11) Google Images: Meckel syndrome type_6 & web \\
\hline
\end{tabular}

\begin{tabular}{|c|c|c|c|}
\hline Net & Link1 & Link2 Link3 Val & Type \\
\hline \multicolumn{4}{|l|}{ Meta } \\
\hline Meckel syndrome type_6 M3970| & Syndrom DABO| & & meta \\
\hline Meckel syndrome type_6 M3970| & Pathosom M7| & $\mathrm{PF} / 2 \mid>$ & meta \\
\hline \multicolumn{4}{|l|}{ Classes } \\
\hline Meckel syndrome type_6 M3970| & Polydactyly syndactyly triphalangism group M3679| & & class \\
\hline
\end{tabular}

\begin{tabular}{|c|c|}
\hline Description & Codel \\
\hline \multicolumn{2}{|l|}{ Definition } \\
\hline \multicolumn{2}{|l|}{ System/Lokalisation } \\
\hline \multicolumn{2}{|l|}{ Struktur } \\
\hline Symptoms & Code 1 \\
\hline \multicolumn{2}{|l|}{ Anamnese } \\
\hline \multicolumn{2}{|l|}{ Vital } \\
\hline +++ Polydaktylie & Polydaktylie 2913R | \\
\hline t++ Nierenzyste & Nierenzyste M5065| \\
\hline \multicolumn{2}{|l|}{ Physikal } \\
\hline \multicolumn{2}{|l|}{ Labor } \\
\hline \multicolumn{2}{|l|}{ Imaging } \\
\hline \multicolumn{2}{|l|}{ Pathologie } \\
\hline $\begin{array}{l}\text { t++ Makroskopie: Enzephalozele: } \\
\text { occipital }\end{array}$ & Enzephalozele 59368X| Hinterhaupt A114| \\
\hline \multicolumn{2}{|l|}{ Genetik } \\
\hline Lead + Mutation: Gen: CC2D2A & $\begin{array}{l}\text { Mutation } 7531 V \text { | Erbanlage 1850Z | coiled-coil and C2 domain containing } \\
\text { 2A 29253H| }\end{array}$ \\
\hline
\end{tabular}


Table 5 Note that each pathosom is part of a hierarchical tree with superset and subsets

\begin{tabular}{|c|c|c|}
\hline Struktı & & \\
\hline Lead & ElementOf: Glomerulonephritis & Glomerulonephritis M2059 \\
\hline+++ & $\begin{array}{l}\text { ElementOf: } \\
\text { Immunkomplexkrankheit }\end{array}$ & Immunkomplexkrankheit $6401 Z$ \\
\hline+++ & $\begin{array}{l}\text { ElementOf: Erkrankung: } \\
\text { Komplementsystem }\end{array}$ & $\begin{array}{l}\text { Krankheit } \underline{\mathrm{DAO1}} \text { complement } \\
\text { 51898L }\end{array}$ \\
\hline+++ & $\begin{array}{l}\text { HasElement: dense deposit } \\
\text { disease }\end{array}$ & MPGN Typ II M5292| \\
\hline+++ & HasVariante: primäre Form & primäre Form 2620Z| \\
\hline+++ & HasVariante: sekundäre Form & sekundäre Form $7570 \mathrm{VI}$ \\
\hline+++ & HasVariante: MPGN Typ I & MPGN Typ I M5880 \\
\hline+++ & HasVariante: MPGN Typ II & MPGN Typ II M5292| \\
\hline+++ & HasVariante: MPGN Typ III & MPGN Typ III M5881| \\
\hline+++ & $\begin{array}{l}\text { HasVariante: C3- } \\
\text { Glomerulonephritis }\end{array}$ & C3-Glomerulonephritis M5293| \\
\hline
\end{tabular}

Note that syntactic differences or language problems are not of interest as "Nierenzyste", "Nierencyste", "renal cyst" and "renal cysts" are all coded by M5065

anemia with an excess of blasts (RAEB) [35]. RAEB exists in three variants, termed RAEB-1, RAEB-2 and RAEB-F, being subsets of the RAEB pathosom. A pathosom is a vector of pathophems. RAEB is a vector with 75 elements (so far) (see Additional file 1: Tables S1 to S4) with three variants. Each pathosom is part of a tree structure. RAEB has three subsets: RAEB-1, RAEB-2 and RAEB-F and is an element of the pathosom myelodysplasia. The tree structure is one of the basic structure for the semantic network and provides "has-attribute" relationships.

\section{Evaluation of the system}

In 90/190 (47.4\%) artificial cases the proposed diagnosis was identified by memem7 (47.6\%). The number of proposed pathosoms (diagnoses) ranged between 0 and 173 with a median of 3 .

\section{Discussion}

Nowadays, it is common sense that both computational linguistics and computer technology will change the practice of medicine fundamentally [39]. However, the evidence, that this change the quality of medicine will improve is sparse [18].

Here, we describe a software system consisting of a pool of pathosoms (disease entities, syndromes, symptoms or sets of disease entities). The goal of this publication is to demonstrate that with some prerequisites a computerassisted assignment of symptoms (in our preliminary system a $5 \mathrm{n}$ tuple) to certain disease entities is possible. The prerequisites are (1) linguistic knowledge is delivered atomistic (2) each pathosom (prototypic disease entity) is considered as a vector (3), and the results of the analysis should be a linguistic game assisting classification of a patient vector to different pathosoms without the use of defined mathematical methods or a distance measure. After the search function of Memem7 a list of possible pathosoms explaining the patient's complaint is given, so far, with focus on linguistic and semantic network heuristics.

For a coming assistance system of decision making in medicine three different tools are mandatory: (1) an electronic history taking which can be transformed in a patient data vector [3-5] or extracts of electronic health care systems (2) a set of disease vectors (in our system called pathosoms) each reflecting a prototypic disease vector or an algorithms for a disease entity. (3) an algorithm comparing the patient vector with all pathosom vectors giving a ranking of possible pathosoms fitting to a given patient vector (inference engine).

Our system termed Memem7 allows today: (1) to construct a prototypic disease vector (2) to have a restricted dialogue with a $5 \mathrm{n}$-tuple of a patient vector. Restricted 
dialogue means that, so far, only 5 tuples can be analyzed by Memem7. After this dialogue, the user is provided with n pathosoms, which fit to the 5-tuple patient vector. The goal of our approach was to demonstrate the feasibility of a knowledge collection in a formalized way.

The mathematical methods used in big data analysis will be of further interest for improving the tools allowing machine assisted medical treatment decision as described by Sun and coworkers, Slack and coworkers and Huang and coworkers [40-42]. Our system covers approximately 4600 medical diagnoses (increasing constantly). Many trials of electronic history taking, even in very sophisticated technical settings as described by Morrison and coworkers [43] are published (70 up to 2010) $([3,4]$, for review $[5,16])$. However, so far, as the authors survey the literature only few open source application of an electronic history taking system are available such as OpenEMR and OpenEHR [44, 45]. In our linguistic game these histories taking systems were replaced by a 5 -tupel. The term linguistic game has some fundamental implications (1) error is part of any game (2) decision can be assisted, but not replaced by a linguistic game (3) a player can improve his results by improving his knowledge (in our system the disease vector of the pathosoms). Therefore, our system may be considered as a third opinion to a given patient vector with so far 5 tuples. Combining memem7 with tools recognizing medical texts like MetaMap [20] or cTake [21] are currently in work.

Can we give any data for accuracy of memem7? In a first testing of the system with up to 5 tuple of search terms we identified the proposed diagnosis of 190 artificial cases for $46.7 \%$. The data available for assessment of the sensitivity for clinical decision support system (CDSS) are sparse and difficult to compare. In one recent publication of Müller and coworkers [46] a sensitivity of $96 \%$ was claimed, when case reports of the New England Journal of Medicine were used for the evaluation of the systems (DXplain, Isabel Healthcare, Diagnosis Pro, PEPID) [47-50]. Our much less impressive data will improve with each new test as the mistakes found in the test are corrected after completing the test. Therefore, the tests are part of a continuous improvement quality circle which provides algorithms to enhance both sematic network and pathophemes (disease symptoms).

What are the differences of Memem7 to other existing medical decisions systems like e.g. HELP [18]. There are different approaches for use of computer-technology in CDSS such as probabilistic, Bayesian approaches or machine learning systems. We add a system based on atomized linguistic terms. It may be possible to combine probabilistic and linguistic approaches. The advantage of a linguistic system is that atomized terms (pathophems) can be easily added to a disease entity. The comparison between a linguistic and a probabilistic approach or its combined use is planned on basis of the next software version.

There are already many systems and tools presented for biomedical text mining and biomedical concept recognition [51, 52]. The systems mainly focus on natural language processing and concept identification through dictionary matching and various machine learning mechanisms. In contrast to these approaches Memem7 is not focused on identifying concepts in natural languages but rather on using such concepts for identification of other complex objects like health disorders. In future, the system might also be able to handle the preprocess of concept identification of written data e.g. medical patient reports. Technically Memem7 is dealing with the problem of matching ambiguous fact concepts (like symptoms, medical events, lab data) with complex concept trees (like anatomy, medical body functions, diseases). Because of the plurivalent nature of the concepts and the heuristic of the algorithms the matching processing is more like a game than a deterministic process.

\section{Conclusions}

In conclusion, we present an electronic system of disease entities, which can enter in a formalized dialog with a patient data vector as proof of concept of a medical navigation system based on a linguistic game.

\section{Additional file}

Additional file 1: Table S1. RAEB part 1. Table S2. RAEB part 2. Table S3. RAEB part 3. Table S4. RAEB part 4. Note that the underscored pathophem (IPSS Score) is not yet included in the system. Table S5. Inflammatory breast cancer part 1. Table S6. Inflammatory cancer part 2. Table S7. Membrano-proliferative glomerulonephritis part 1. Table S8. membrano-proliferative glomerulonephritis part 2. (DOCX $174 \mathrm{~kb}$ )

\begin{abstract}
Abbreviations
ATC: Anatomical therapeutic chemical classification; CAS: Common chemistry data base; CDSS: Clinical decision support system; DIMDI: Deutsches Institut für medizinische Dokumentation; EC: Brenda, comprehensive enzyme information system; HGNC: Hugo gene nomenclature committee 2015); HTML5: Hypertext markup language; ICD-10: International classification of diseases, injuries and causes of death; ICD-O: International classification of diseases, oncology; LOINC: Logical observation identifiers and names; MPNG: Membrano-proliferative glomerulonephritis; OMIM: Online Mendelian Inheritance in Man; OPS: Operationen-und Prozedurenschlüssel-Internationale Klassifikation der Prozeduren in der Medizin 2015; ORPHANET: Portal für seltene Krankheiten und Orphan Drugs; RAEB: Refractory anaemia with excess blasts; TA: Taxonomy of anatomy; WHO: World Health Organization
\end{abstract}

\section{Acknowledgements}

We appreciate the long-standing and ongoing support of the Robert Bosch Foundation for the improvement of medical practice. 


\section{Availability of data and materials}

Availability of data and materials: the system is in a proof-of-concept state and provides a limited test environment access. The datasets used and/or analyzed during the current study are available from the corresponding author on reasonable request.

\section{Authors' contributions}

PF was responsible for the input of medical knowledge, conceptual work, testing the system, preparing of the manuscript. AK was responsible for writing of the software, conceptual work and preparing of the manuscript. PA was engaged in writing of software and conceptual work. FK achieved the input of orphan diseases. CF was testing the system and worked on the input of medical knowledge. MDA achieved the conceptual work and was engaged in preparing the manuscript. All authors were involved in the reading of the manuscript and gave intellectual input to all stages of the preparation of the manuscript. All authors read and approved the final manuscript.

\section{Competing interests}

Dr. Peter Fritz: No competing interest.

Dr. Andreas Kleinhans: No competing interest.

Dipl-Inf. Patrick Albu: No competing interest.

Florian Kuisle: No competing interest.

Dr. Christine Fritz-Kuisle: No competing interest.

Prof. Mark Dominik Alscher: No competing interest.

\section{Consent for publication}

Not applicable.

\section{Ethics approval and consent to participate}

As no patient data are included in the publication, no ethic approval is necessary following the laws. All artificial patients are imagined by the help of textbooks of medicine. The ethical board of Baden-Wuerttemberg is responsible with bylaws stated in "Gesetz über das Berufsrecht und die Kammern der Ärzte, Zahnärzte, Tierärzte, Apotheker, Psychologischen Psychotherapeuten sowie der Kinder- und Jugendlichenpsychotherapeuten (Heilberufe-Kammergesetz - HBKG) in der Fassung vom 16. März 1995 (GBI. BW v. 17. Mai 1995 S. 314)".

\section{Publisher's Note}

Springer Nature remains neutral with regard to jurisdictional claims in published maps and institutional affiliations.

\section{Author details}

'Department of Clinical Pathology, Robert-Bosch-Hospital, Stuttgart, Germany. ${ }^{2}$ Department of General Internal Medicine and Nephrology, Robert-Bosch-Hospital, Auerbachstrasse 110, D-70376 Stuttgart, Germany. ${ }^{3}$ Klinikum Günzburg, Abteilung für Anästhesie, Günzburg, Germany.

\section{Received: 2 September 2016 Accepted: 13 June 2017}

Published online: 10 July 2017

\section{References}

1. Graber ML. The incidence of diagnostic error in medicine. BMJ Qual Saf doi. 2013. 10.1136/bmjqs-2012-001615

2. Sadegh-Zadeh K. Handbook of analytic philosophy of medicine. Hamburg: Springer Verlag; 2012.

3. Zakim D, Braun N, Fritz P. Alscher MD. Underutilization of information and knowledge in everyday medical practice: Evaluation of a Computer-based Solution. BMC Med Inform Decis Mak. 2008;8:50.

4. Zakim D, Fritz C, Braun N, Fritz P, Alscher MD. Computerized History-Taking as a Tool to Manage LDL-Cholesterol. Vasc Health Risk Manag. 2010;6:1039-46.

5. Zakim D. Development and significance of automated history-taking software for clinical medicine, clinical research and basic medical science. J Intern Med. 2016. doi:10.1111/joim.12509

6. Mayne JG, Weksel W, Sholtz PN. Toward automating the medical history. Mayo Clin Proc. 1968:43:1-25.

7. Coombs GJ, Murray WR, Krahn DW. Automated medical histories: factors determining patient performance. Comput Biomed Res. 1970;3:170-81.

8. Linder F. Pathways to surgical diagnosis. Ann R Coll Surg Engl. 1971;49:178-93.
9. Roizen MF, Coalson D, Hayward RS, Schmittner J, Thisted RA, Apfelbaum JL, Stocking CB, Cassel CK, Pompei P, Ford DE. Can patients use an automated questionnaire to define their current health status? Med Care. 1992;30:74-84.

10. Wenner AR, Ferrante M, Belser D. Instant medical history. Proc Annu Symp Comput Appl Med Care. 1994;1036.

11. Wald JS, Rind D. Computer-based patient records. N Engl J Med. 1996;334:1139.

12. Kim JA. A comparative study of nursing diagnosis systems using neural networks and expert systems. Stud Health Technol Inform. 1997;46:404-7.

13. Reilly CA. Examining the symptom experience of hospitalized patients usig a pen-based computer. Proc AMIA Symp. 1999;364-368

14. Pierce B. The use of instant medical history in a rural clinic. Case study of the use of computers in an Arkansas physician's office. J Ark Med Soc. 2000;96:444-7.

15. Fritz-Kuisle C. Medical thesis. Vergleich eines computerbasierten Expertensystems (CLEOS) mit konventioneller Krankheitsbeschreibung (Anamnese und Arztbrief) unter besonderer Berücksichtigung des kardiovaskulären Risikos, des Impfstatus und der Komorbiditäten. Tübingen: Inaugural-Dissertation Universität Tübingen; 2012.

16. Bacher S. Medical thesis. Erfahrungen mit einer elektronischen Anamnese in einer nephrologischen Facharztpraxis. Tübingen: Inaugural-Dissertation Universität Tübingen; 2013.

17. Spooner SA. Mathematical foundations of decision supprot systems. In: Elis S. Berner. Clinical Decision Support Systems. Theory and Practice. Hamburg: Springer second edition; 2007.

18. Haug PJ, Reed M, Gardner R, Evans S, Rocha BH, Rocha RA. Clinical decision support at the intermountain healthcare. In: Elis S. Berner. Clinical Decision Support Systems. Theory and Practice. Hamburg: Springer second edition; 2007

19. Jia PL, Zhang PF, Li HD, Zhang LH, Chen Y, Zhang MM. Literature review on clinical decision support system reducing medical error. J Evid Based Medicine. 2014;7:219-26.

20. Metamap - A Tool for Recognizing UMLS Concepts in Text. https://metamap. nim.nih.gov/

21. CTake. Apache CTAKES $^{\mathrm{TM}}$ - clinical Text Analysis Knowledge Extraction. http://ctakes.apache.org/

22. DIMDI - Deutsches Institut für Medizinische Dokumentationhttps://www. dimdi.de/

23. ICD-10-GM DIMDI Deutsches Institut für Medizinische Diagnostik. www.dimdi. de/de/klassi/icd-10-gm/index.htm.

24. ICD-O. http://www.dimdi.de/static/de/klassi/icdo3/index.htm.

25. ORPHANET. Das Portal für seltene Krankheiten und Orphan Drugs. www. orpha.net/consor/cgi-bin/index.php?lng=DE

26. TA. Terminologia Anatomica. International Anatomical Terminology. Thieme, Stuttgart 1998, ISBN 3-13-114361-4.

27. OPS. International statistische Klassifikation der Krankheiten und verwandter Gesundheitsprobleme. 2015. https://www.dimdi.de/de/klassi/ops/index.htm

28. OMIM. Online Mendelian Inheritance in Man. McKusick-Nathans Institute of Genetic Medicine, Johns Hopkins University (Baltimore). http://omim.org/

29. CAS. Common chemistry data base. http://www.commonchemistry.org

30. EC. Brenda. The Comprehensive Enzyme Information system www.brendaenzymes.org/

31. HGNC. Hugo gene nomenclature system. www.genenames.org

32. ATC. Anatomical Therapeutic Chemical Classification. https://loinc.org.

33. LOINC. Logical Observation Identifiers andNames. https://search.loinc.org/

34. R Development Core Team. R: A language and environment for statistical computing. R Foundation for Statistical Computing, Vienna, Austria. ISBN 390061-07-0; 2008. Version 3.1.1.

35. Swerdlow SH, Campo E, HarrisNL JES, Pileri SA, Stein H, Thiele J, Vardiman JW. WHO classification of tumours of haematopoetic and lymphoid tissue. Lyon: International Agency for Reseach and Cancer; 2008.

36. Warman L, Cormier-Daire V, Hall C, Krakow D, Lachman R, LeMerrer M, Mortier G, Mundlos G, Nishimura G, Rimoin DL, Robertson S, Savariirayan R, Sillence D, Spranger J, Unger S, Zabel B, Superti-Furga A. Nosology and classification of genetic skeletal disorders: 2010 revision. Am J Med Genet Part A. 2011;155:1-56

37. Meckel Syndrom typ VI. http://www.omim.org/entry/612284

38. Kuhlmann U, Böhler J, Luft FC, Alscher MD, Böhler J. Nephrologie. 6th ed. Verlag: Thieme; 2015.

39. Alscher MD. Computereinsatz in der Medizin: Chance für eine hochwertige Versorgung. Dtsch Arztebl. 2008;105:1897-900.

40. Slack W. Patient-computer dialogue: a hope for the future. Mayo Clinic Proc. 2010;85:701-3.

41. Sun J, Wang F, Hu J, Edabollahi S. Supervised patient similarity measure of heterogeneous patient records. SIGKDD. 2015;14:16-24. 
42. Huang T, Lan L, Fang X, An P, Min J, Wang F. Promises and challenges of big data computing in health sciences. Spec Issue Comput Bus Health Sci. 2015;2:2-11. http://www.sciencedirect.com/science/article/pii/ S22145796150000118.

43. Morrison-Beedy D, Carey MP, Tu X. Accuracy of audio-computer-assistedself-interviewing (ACASI) and self-administered questionnaire for the assessment of sexual behavior. AIDS Beha. 2006;10:541-52.

44. OpenEHR: http://www.openehr.org/what_is_openehr.

45. OpenEMR: www.open-emr.org

46. Müller T, Jerrentrup A, Fritsch HW, Schäfer J. Software zur Unterstützung der Differentialdiagnose in der Inneren Medizin. Auswirkung auf die Qualität der Medizin. Klinikarzt. 2016;45:250-6.

47. IsabelHealth: htpp://www.isabelhealthcare.com

48. DiagnosisPro: htpp://https://en.wikipedia.org.wiki/DiagnosisPro

49. DXPlain: www.mghlcs.org/projects/dxplain

50. PEPID: www.pepid.com

51. Leal A, Goncalves D, Martins B, Couto FM. Lisboa U: Identification and classification of medical concepts. Proceedings of the 8th International workshop on Semantic Evaluation 2014. p. 711-715.

52. Campos D, Matos S, Oliveira JL. A modular framework for biomedical concept recognition. BMC Bioinformatics. 2013;14:281.

Submit your next manuscript to BioMed Central and we will help you at every step:

- We accept pre-submission inquiries

- Our selector tool helps you to find the most relevant journal

- We provide round the clock customer support

- Convenient online submission

- Thorough peer review

- Inclusion in PubMed and all major indexing services

- Maximum visibility for your research

Submit your manuscript at www.biomedcentral.com/submit
Biomed Central 